\title{
Norms of judgement, naturalism, and normativism about content
}

\author{
E. Diaz-Leon ${ }^{*}$ \\ Department of Logic, History and Philosophy of Science, University of Barcelona, \\ Barcelona, Spain
}

\begin{abstract}
David Papineau (1999) argues that norms of judgement pose no special problem for naturalism, because all such norms of judgement are derived from moral or personal values. Papineau claims that this account of the normativity of judgement presupposes an account of content that places normativity outside the analysis of content, because in his view any accounts of content that place normativity inside the analysis of content cannot explain the normativity of judgement in the derivative way he proposes. Furthermore, he argues that normative accounts of content along those lines are independently problematic. In this paper I aim to respond to both objections, by arguing that normative accounts of content can be seen as naturalist accounts, even if they place normativity inside the analysis of content; and that normative accounts of content are compatible with a derivative account of norms of judgement of the sort Papineau advocates.
\end{abstract}

Keywords: theories of content; normativity; aim of belief; naturalism.

\section{Introduction}

David Papineau (1999) aims to argue that norms of judgement do not pose a special problem for the naturalist. By 'norms of judgement', he refers to claims about the way judgements ought to be made. His main strategy is to argue that all norms of that sort are derived from moral or instrumental values, so that they do not involve any sui generis form of normativity. In particular, he argues that norms of judgement can be seen as "prescriptions to the effect that, in order to achieve the truth, you ought to judge in suchand-such ways" $(1999,18)$. Forming true beliefs might have moral or instrumental value, but in either case, he contends, we can derive norms of judgement of the form 'you ought

\footnotetext{
*Email: ediazleon@ub.edu
} 
to judge in such and such ways' from the fact that one values achieving the truth. Of course, this strategy gives rise to the question of what explains moral and instrumental value. But at least it is clear that, if we can derive all norms of judgement from moral and instrumental value, as Papineau suggests, this shows that norms of judgement do not pose any sui generis form of normativity, over and above moral and instrumental normativity, so there is no additional sort of normativity here to worry the naturalist. According to Papineau, there is nothing essentially normative about truth: "Truth is in the first instance a descriptive property, like car-speed or celibacy. ... it may be personally desired or morally valuable, in given contexts, but that is additional to its nature" (20). Interestingly, Papineau claims that this sort of strategy assumes a certain kind of analysis of mental content:

I am taking a stand against those approaches to content which place normativity inside the analysis of content, in the sense that they presuppose sui generis norms governing judgement in explaining truth-conditional content, and hence truth. Let us call theories of this kind 'non-naturalist' theories of content. (20).

In this paper I want to argue, contra Papineau, (i) that some approaches to content which place normativity inside the analysis of content can actually be seen as naturalist theories of content; and (ii) that theories of this sort are actually compatible with the reductivist account of norms of judgement that he advocates, and therefore, theories of content of that sort do not necessarily have to posit a problematic, sui generis form of normativity that might worry the naturalist. In short, I want to argue that it is possible to have it both ways: it is possible to defend a theory of content in terms of content-constituting norms, 
and at the same time to maintain that all norms of judgement are derived from moral or personal values.

\section{Normative theories of content and naturalism}

To start our discussion, I want to examine the question of whether accounts of content that place normativity inside the analysis of content (that is, accounts of content that appeal to content-constituting norms) are necessarily non-naturalistic. In my view, Papineau seems to be conflating the distinction between naturalistic and non-naturalistic theories of content, on the one hand, with the distinction between theories that appeal to content-constituting norms and those that do not, on the other. For instance, he says:

I am happy to agree that non-naturalist theories of content imply the existence of prior judgemental norms that resist appropriation 'within a naturalism that conceives of nature as the realm of law', in that non-naturalist theories postulate a peculiar species of content-constituting norms which appear mysterious form a naturalist perspective. But naturalist theories of content don't accept the existence of such special content-constituting norms, since naturalist theories explain content without any reference to such prior norms. They place the norms of judgement outside the theory of content. (22)

In response, I want to argue that theories of content that appeal to content-constituting norms are not necessarily incompatible with naturalism. In particular, I will focus on those theories of content which take content to depend at least in part on facts about when it is reasonable to form a belief (which Papineau calls "Davidsonian theories of content" $[20])^{1}$. According to Papineau, one of the problems for theories of content of this sort is that "there seems to be little alternative... except to hold that the norms of judgement are 
primitive and not to be further explained" (28). In response, I will argue that there is an alternative: it is possible to explain the content-constituting norms posited by theories of content of this sort in purely descriptive, non-normative terms. Therefore, these theories do not have to posit any form of primitive, sui generis normativity in order to explain content. (Furthermore, in the next section I will argue that they can also explain all norms of judgement as being derived from moral and personal values, so there is no reason to think that these theories of content need to hold that norms of judgement are primitive.)

In order to build my case for this claim, I am going to focus on one specific account of content of the sort that Papineau is focusing on-that is, accounts that place normativity inside the analysis of content-namely, Ralph Wedgwood's normative account of content. According to Wedgwood's view, "the nature of every concept is given both by the principle that specifies when beliefs involving the concept are correct, and also by certain basic principles of rationality that specify certain ways of using the concept as rational" $(2007,86)$. He adds:

Thus, for example, the nature of logical concepts, like 'if' and 'not' might be given both by their semantic values - their contribution to the truth-conditions of contents in which they appear - and also by the basic principle that it is rational (at least in the absence of any special reason for doubt) to accept instances of certain fundamental rules of inference for these logical concepts. The nature of the concept 'yellow' might be given both by the concept's semantic value - the property of yellowness that the concept stands for - and also by the basic principle that it is rational to make a judgement applying this concept to some perceptually presented object if one has a visual experience that represents that object in a certain distinctive way. (86-87) 
I take it that this account clearly counts as an account of content that places contentconstituting norms inside the analysis. My question is then: is this account compatible with naturalism about norms of judgement? As we will see, this depends on how the account is spelled out. Wedgwood himself seems to suggest that, on his account, content is essentially normative, that is, the content-constituting norms cannot be understood in non-normative, purely descriptive terms. For instance, he says: "any adequate account of the nature of intentional mental states must employ normative terms (or at least must mention the properties and relations that these normative terms stand for)" (85-86). In a more recent paper, he states the view as follows:

$[I] n$ giving an account of the essence or nature of intentional states we must mention these normative properties or relations. Equally, in giving an account of the nature of an intentional fact ... we must state some normative fact. ... On this understanding, then, the claim that the intentional is normative is a metaphysical claim concerning the nature or essence of intentional states... . It is not a semantic thesis about the meaning of intentional terms... . It could be that even if we ordinarily think of intentional states as states that we "ought" to be in under such-andsuch circumstances, the nature or essence of those states can be explained in wholly nonnormative terms. (2009, 422-423)

Here, Wedgwood wants to make clear that he is not just advocating a semantic theory about the meaning of intentional terms, but rather a metaphysical theory about the (essentially normative) nature of intentional states. In contrast, I want to defend a version of the normative account of content according to which it is both true that (a) in giving an account of the nature of content we must mention normative properties and relations (because, as a matter of metaphysical necessity, such contents can be instantiated only if 
certain normative properties and relations are instantiated), and (b) these normative properties and relations that are necessary for the instantiation of intentional states can be explained in wholly non-normative terms. How can we make this view consistent? Here is one way in which these two claims could be true at the same time: we can imagine a (physical) system that instantiates some relevant intentional states. According to the normative account of content, these intentional states are constituted at least in part by normative properties or relations that the system instantiates. This, I take it, is enough to satisfy (a): if the system's intentional states are partly constituted by normative properties or relations, then an exhaustive account of the nature of those intentional states must mention those normative properties or relations (even if these normative properties and relations are not themselves fundamentally normative, and can be described in nonnormative terms). This account of the intentional states of the system, I submit, is perfectly compatible with a reductivist account of the nature of those normative properties and relations: just because we have characterized intentional states in a way that makes essential use of normative properties and relations, this does not mean that those normative properties and relations are a fundamental, sui generis, primitive fact about the world. Compare: someone might defend a psychological account of social phenomenon $\mathrm{X}$ (say, an account of that social phenomenon in terms of collective intentionality). That is, they might claim that phenomenon $\mathrm{X}$ is partly constituted by psychological properties and relations, so that in order to give an account of phenomenon $\mathrm{X}$, we must mention psychological properties and relations. This is a metaphysical account of the nature or essence of $\mathrm{X}$ : social phenomenon $\mathrm{X}$ cannot be instantiated without the instantiation of those psychological properties and relations. However, this 
does not entail that psychological properties must be a fundamental, primitive fact about the world. This account of social phenomenon $\mathrm{X}$ in terms of psychological properties is perfectly compatible with a reductivist account of psychological properties in terms of natural properties.

The next question then is: how could we defend an account of content along these lines? My answer here is basically that we can endorse much of what Wedgwood says, without endorsing his further claim that there is no way of specifying the nature of the content-constituting norms in wholly non-normative terms. Following Wedgwood, the account of content that I am suggesting is an account of the nature of concepts in terms of some normative principles that apply to mental states involving those concepts. It will be useful to consider what has to be true of a thinker if she is to possess these concepts, according to the normative account of concepts I am suggesting: the thinker must have some dispositions that amount to an appropriate sort of sensitivity to the normative principles that give the nature of the concept in question. As Wedgwood puts it:

[T] he sort of disposition that a thinker must have, if she is to possess a given concept, is a disposition to think in ways that the relevant basic principle of rationality specifies as rational. ... Then, the disposition one must have, in order to posses the concept, will be a disposition to respond to one's actually being in those antecedent mental states by forming that further mental state. ... According to this version of the claim that the "intentional is normative", this disposition is essential to possessing the concept 'yellow'. (2007, 87-88)

The final question I need to address, in order to defend the coherence of an account of content that satisfies both (a) and (b) above, is this: can we specify the nature of this 
disposition in wholly non-normative terms? Wedgwood argues it is not possible. His argument goes as follows: Some opponents of the normative account of content argue that even if it is true that an account of what is essential to a given concept will have to mention normative properties or relations, it is still possible for such an account to single out the relevant essentially rational disposition in virtue of some purely non-normative features of the mental $\operatorname{state}^{2}(2009,432)$. However, he argues, there seems to be no way to specify the relevant sorts of rational reasoning without mentioning normative properties or relations:

The specification that I have just given of the sort of reasoning that leads from visual experiences to beliefs of the form ' $\mathrm{x}$ is yellow' included a proviso "in the absence of any positive reason to believe one's experience to be unreliable". But in specifying this sort of reasoning in this way, I mentioned the normative relation of having a reason to believe something. ... There seems to be no way of specifying these defeating conditions without mentioning normative properties or relations. (433)

That is, the worry here seems to be that in order to identify the correct dispositions that determine the content of a given concept, we need to appeal to some "no defeaters" clauses, otherwise our account of content would be incorrect. But of course, the argument goes, these "no defeaters" clauses essentially involve normative language, and therefore there is no way of specifying the correct dispositions in wholly non-normative terms.

Wedgwood anticipates one possible objection to this argument (which I want to develop in what follows), but he argues it is not a good objection: 
Some philosophers might suggest that one could still be disposed to reason in accordance with these essentially rational forms of reasoning even if the normative properties or relations do not have to be mentioned in specifying these dispositions themselves. For example, one might have a host of separate dispositions, such that the net effect of all these separate dispositions is that one forms and revises one's beliefs and other attitudes in just the same way as one would if one had a disposition that actually responded to the normative facts themselves. However if all these dispositions really are quite separate and causally independent of each other, then it seems that it could be just a fluke that the net effect of all these dispositions is that one forms and revises one's attitudes in a rational way. But in that case, it actually seems to me quite doubtful whether the manifestation of these dispositions can really count as rational thinking at all. (434).

The response on behalf of the naturalist version of the normative account that is suggested here seems to go as follows: even if we accept that in order to pick out the correct dispositions we typically appeal to "no defeaters" clauses that use normative language, it would be possible for a subject described in wholly naturalistic terms to behave as if she were responding to those normative principles, and moreover we could appeal to the dispositions underlying those responses in order to fix the content of the relevant concepts. This seems to be a very promising strategy, but Wedgwood argues that it is problematic because all these underlying dispositions would probably be causally separate, and therefore it is just a matter of luck that the subject is responding as if she were following the rational principles, and hence cannot be said to be genuinely rational.

I find this line of response very puzzling, for two reasons: First, why should we assume that all the dispositions that are responsible for someone's forming and revising beliefs and attitudes in the appropriate way are quite separate and causally independent of each other? This does not seem to be a plausible account of how physical systems are 
capable of performing those tasks. Second, even if those dispositions were in fact causally independent, would this mean that the overall effect of those dispositions cannot really count as rational thinking at all? Why not? Here Wedgwood seems to be assuming that a purely physical, complex mechanism that performs certain tasks by means of a combination of separate causal mechanisms could not really count as a rational thinker. But this seems to beg the question against the naturalist account of the normativity of content that I am trying to suggest here. Therefore, I think there is no good reason here to reject the claim that it is possible to describe the relevant dispositions in non-normative terms, and therefore Wedgwood's objections against an account of content in terms of normative properties and relations of the sort I am proposing, which maintains that these normative properties and relations can ultimately be specified in wholly non-normative terms, are not successful.

\section{Derivative norms of judgement}

The next question I need to address is this: Is a normative account of content along these lines compatible with Papineau's strategy for dealing with norms of judgement, according to which all norms of judgement are derived from moral and personal values?

It might seem that a normative account of content of the sort I am proposing is not compatible with Papineau's strategy. For instance, he claims:

[Naturalist theories of content] place the norms of judgement outside the theory of content, and hold that content and truth are constituted independently of facts of the form 'you ought to judge in such-and-such ways'. Given this, they can then account for such norms of judgement 
straightforwardly, holding that all the 'oughts' involved are derived oughts, arising when moral or personal value is attached to the independently constituted aim of truth. $(1999,22)$

This seems to suggest that theories of content that hold that content is constituted in part by facts of the form 'you ought to judge in such-and-such ways' cannot then account for such norms of judgement in the same straightforward manner. In response, I think that normative theories of content (of the sort I am advocating) can endorse an account of norms of judgement that is essentially the same as Papineau's. In particular, they can accept the claim that all norms of judgement of the form 'you ought to judge in such and such ways' (for instance, that you ought to apply the concept 'yellow' to some perceptually presented object if one has a certain kind of visual experience of the object) are derived from personal and moral values. That is, such norms of judgement only apply to you when you already value achieving the truth. ${ }^{3}$

But—one might argue — isn't it true that, according to the normative account of content, if you have the concept 'yellow' that is because you have the disposition to form judgements in a way that is sensitive to that norm? Answer: yes, that is what (partially) determines that you have the concept 'yellow' (rather than a different concept). But as far as I can see, this does not entail that you ought to reason in that way. The normative account of content only entails that you are in fact disposed to reason in that way (if you have the corresponding concept). And this is why, contra Papineau, normative accounts of content are compatible with Papineau's account of epistemic norms as being derivative from moral and instrumental norms: we can hold that in order to possess a certain concept (and to entertain thoughts that involve that concept) one needs to have the disposition to be sensitive to certain rational principles about how one ought to reason, 
but this is compatible with the claim that the fact that one ought to reason in a certain way is always derivative from the moral and instrumental norms that apply to that subject.

It might be argued here that my account does not do justice to normative accounts of content, since I am merely saying that in order to entertain a certain concept or content, one must be disposed to form beliefs according to certain principles of rationality. But I do not want to accept the further claim that if one entertains that content (that is constituted by those principles of rationality), then it would be rational to follow those principles, and irrational not to follow them. Or in other words, I am denying the claim that if one entertains some content, one thereby has the (epistemic) obligation to reason in certain ways. I cannot endorse this claim precisely because this would be incompatible with Papineau's derivative account of norms of judgement. That is, this derivative account denies that there are some norms of rationality that apply to a subject, just in virtue of entertaining some content. I am saying that all forms of rationality are such that they apply to a subject only relative to the moral and prudential values that they already have. So the worry is this: can I endorse a version of normativism about content that is "normative" enough, given that I do not want to endorse the crucial claim that if one possesses, say, the concept 'yellow', one is thereby in a position such that they ought to reason in certain ways, regardless of their moral and personal values? In response: I agree that I cannot endorse this further claim, and if someone wanted to say that normativism about content includes this view, then my account here could not be a version of normativism properly speaking. But this seems to be a terminological difference. In my view, the central claim of normativism is the claim that concepts are constituted by dispositions to reason in certain ways. This is a claim about the nature of those concepts, 
that is to say, a claim about what grounds those concepts. For example, if one possesses the concept 'yellow', this is grounded (at least in part) in the fact that one has a disposition to follow certain inferential principles. As I have argued, the additional claim that if one possesses the concept 'yellow', then one ought to reason according to those inferential principles, is incompatible with Papineau's plausible account about the derivative nature of norms of judgement. My main point here is that the central claim of normativism about content (i.e. the claim that concepts are constituted in part by dispositions to be sensitive to inferential principles) is compatible with Papineau's account of the derivative nature of norms of judgement. In addition, I believe that this central claim of normativism about concepts does not entail the additional claim that subjects that possess those concepts thereby ought to reason in certain ways, according to a fundamental, non-derivative form of normativity. If someone wanted to endorse this view, it would need additional motivation. ${ }^{4}$

Relatedly, Papineau mentions a similar worry regarding accounts of content that appeal to both content-constituting norms, and derived norms of judgement:

Naturalists ... want to construe all norms relating to beliefs as derived imperatives... . Nonnaturalists, by contrast, hold that at least some norms are prior, sui generis and non-derived, and moreover that these prior norms underpin the constitution of content for beliefs. But this means that non-naturalists of any kind are going to be threatened with some doubling of norms. For there will always be room for corresponding derived norms, orientated to the value of truth... alongside whichever norms non-naturalists take to be primitive and content-constituting. (37) 
In response, I believe that this doubling of norms is not problematic, because the norms have a different explanation in each case. In the case of content-constituting norms, these are norms that are needed to specify the dispositions that determine content: we explain content in terms of dispositions to be sensitive to such-and-such norms (where these dispositions can also be specified in wholly non-normative terms, as I argued in the previous section). On the other hand, the derived norms are those norms of judgement that follow from the moral and personal values that one has. As I have suggested, these two sets of norms could come apart in some particular cases. For instance, one subject (let's call her Jane) might possess the concept 'yellow', such that she has a disposition to form judgements of the form ' $\mathrm{x}$ is yellow' in the presence of certain experiences (and in the absence of defeating conditions), but at the same time there are no relevant moral and personal values that entail that Jane ought to form judgements in such a way. On the other hand, a different subject (let's call her Maura) might possess a faulty concept of 'yellow', such that she is not sensitive to the corresponding norms, but at the same time, it might be required (given her moral and personal values) that Maura forms judgements according to such norms. ${ }^{5}$ In ideal cases, a subject will in fact be disposed to be sensitive to the norms that she ought to be sensitive to, given her moral and personal values. But I do not think that this "doubling" of epistemic norms is problematic at all.

Furthermore, Papineau discusses a similar example, in order to illustrate his concern with normative accounts of content of the sort I am advocating. He says:

Suppose an elderly man realizes he is likely to be upset if he learns about the real probability of his developing cancer, and so arranges to avoid any evidence that might undermine his sanguine belief that this probability is low. Or suppose an adolescent youth learns that people with an 
inflated view of their own worth are generally happier and more successful, and so deliberately seeks out evidence which will make him think overly well of himself. (24)

According to Papineau's account of epistemic norms as derivative from moral and instrumental values, it follows that these subjects have some reasons for holding their false beliefs, or in other words, that they are doing what they ought to be doing (in the epistemic sense). But according to Papineau, this claim will be at odds with normative accounts of content, according to which there are some content-constituting norms, "[f]or such theories make it constitutive of your possessing a belief with a certain truth condition that you be subject to norms which are apt to guide you to the truth" (24). That is, the concern is that normative theories of content will have it that the subjects in the examples above always have some reasons for seeking evidence or forming beliefs in a way that will lead them to form true beliefs about the matter at issue, regardless of their moral and instrumental values, which is precisely what the derivative account of the normativity of judgement defended by Papineau denies. According to Papineau, it follows from normative accounts of content that "if you believe that you have a lower chance of cancer, or that you are blessed with above-average attributes, then the norms which constitute these beliefs will apply to you, and so you won't be thinking as you ought to" (24). In response, I believe that normative accounts of content do not really have this consequence. In particular, I believe that even if it is true that those beliefs are constituted in part by those truth-conducive norms, it does not follow that those norms apply to those subjects and therefore that they ought to follow those norms no matter what, in the relevant sense of (derived) epistemic normativity that Papineau is focusing on. As I suggested above, in my view the normative account of content is perfectly 
compatible with Papineau's plausible claim that one ought to judge in certain ways in order to achieve the truth only provided that they already value achieving the truth, given their moral and instrumental values. In particular, this is perfectly compatible with the view that possessing certain concepts and entertaining the corresponding thoughts is constituted in part by having a disposition to follow certain principles of rationality. For example, in the examples above, if the subjects have those beliefs (e.g. that his chances of getting cancer are low, or that he is blessed with above-average attributes), and in particular if they possess the constituent concepts, that is in part because they are disposed to be sensitive to certain truth-conducive norms; but at the same time, it can also be the case that, given their moral and personal values, they ought not to follow those truth-conducive norms in this particular occasion, and in particular they ought to form those false beliefs instead (because they will increase their health, or their happiness, which they happen to value more than truth), even if those beliefs are contrary to the available evidence. ${ }^{6}$

In other words, what I am suggesting is that there are two different ways in which these principles of rationality can be said to apply to a subject: first, in virtue of the subject possessing some concepts (and therefore, being in fact disposed to follow the corresponding content-constituting principles), and second, in virtue of her moral and instrumental values, which make it the case that she ought to form certain beliefs regarding a certain matter (because they have moral or prudential value for her), and therefore that she ought to reason according to those principles. I do not think that this consequence of the combination of views that I am suggesting here (that is, a normative account of content plus a derivative account of norms of judgement) would have to count 
as a reason against this combination of views. On the contrary, I take this to be an interesting discovery about our notion of epistemic normativity.

\section{Conclusion}

In this paper I have provided reasons to doubt the following two claims: (i) normative accounts of content are not able to explain the normativity of judgement in the derived way that Papineau proposes, and (ii) normative accounts of content are incompatible with naturalistic approaches to content. In particular, I have argued for the following theses: (a) normative accounts of content can be seen as naturalist accounts, even if they place normativity inside the analysis of content; (b) explanations of the nature of content in terms of (content-fixing) inferential dispositions are not really committed to the existence of primitive norms of judgement; and (c) the "doubling" of norms that would arise from normative accounts, according to Papineau (i.e., the norms of judgement that determine content, on one hand, plus the extra derived norms that arise from personal and moral values, on the other) is not really problematic, because we need to posit norms of both kinds anyway.

\section{Acknowledgements}

I am grateful to the Social Sciences and Humanities Research Council of Canada for financial support. I have presented ancestors of this paper at the University of Manitoba, the Canadian Society for Epistemology at the University of Sherbrooke, and the Joint Session of the Aristotelian Society and the Mind Association at the University of Cambridge. I am very grateful to audiences on those occasions for very useful feedback. I am especially indebted to the following for very helpful comments and discussion: Saray Ayala, Murray Clarke, Alex Davies, Jonathan Jenkins Ichikawa, Shawn Jordan, Meena 
Krishnamurthy, Dan López de Sa, Carl Matheson, David Papineau, Sven Rosenkranz, and Chris Tillman. Thanks also to several anonymous reviewers for useful suggestions.

\section{Notes on contributor}

E. Diaz-Leon is a Ramon y Cajal Researcher at the University of Barcelona. Before this, she was an Assistant and then Associate Professor at the University of Manitoba. She specializes in philosophy of mind and language and philosophy of gender and race, and she also has interests in metaphysics and epistemology. She has published her work in journals such as Australasian Journal of Philosophy, Ergo, European Journal of Philosophy, Hypatia, Mind, Philosophical Studies, and Ratio.

\section{References}

Boghossian, Paul. 2003. "Blind Reasoning." Proceedings of the Aristotelian Society 77 (Sup. Vol.): $22-248$.

Papineau, David. 1999. "Normativity and Judgement." Proceedings of the Aristotelian Society 73 (Sup. Vol.): 16-43.

Papineau, David. 2013. "There Are No Norms of Belief." In The Aim of Belief, edited by T. Chan, 6-79. Oxford: Oxford University Press.

Shah, Nishi. 2003. "How Truth Governs Belief." Philosophical Review 112 (4): 447-82.

Shah, Nishi, and J. David Velleman. 2005. "Doxastic Deliberation." Philosophical Review 114 (4): 497-534.

Wedgwood, Ralph. 2002. "The Aim of Belief.” Philosophical Perspectives, no. 16: 267-297.

Wedgwood, Ralph. 2007. "Normativism Defended." In Contemporary Debates in Philosophy of Mind, edited by B.P. McLaughlin and J. Cohen, 85-101. Oxford: Blackwell.

Wedgwood, Ralph. 2009. "The Normativity of the Intentional." In The Oxford Handbook of Philosophy of Mind, edited by B.P. McLaughlin, A. Beckermann, and S. Walter, 421-436. Oxford: Oxford University Press.

Zalabardo, José L. 2010. "Why Believe the Truth? Shah and Velleman on the Aim of Belief." Philosophical Explorations 13 (1): 1-21.

\footnotetext{
${ }^{1}$ See Boghossian (2003) for an excellent defence of a theory of content along these lines.

${ }^{2}$ As we will see, this is exactly the possibility that I want to defend here.

${ }^{3}$ According to Papineau, then, one possible challenge to derivative accounts of norms of judgement arises from normative accounts of content. In addition, there is a second challenge that arises from normative
} 
accounts of belief, that is to say, views to the effect that it is part of the concept of belief that it aims at truth, and therefore if someone forms a belief by means that are not truth-conducive, she is not doing what she ought to do in some fundamental, non-derivative sense, that is, regardless of whether she already values achieving the truth given her moral and personal values. In this section, I want to focus on the first sort of challenge, regarding normative accounts of content, and I want to argue that normative accounts of content are actually not in tension with derivative accounts of norms of judgement, so there is no real challenge here. On the other hand, I agree that a normative account of belief of the sort sketched above would indeed be in tension with a derivative account of norms of judgement, but this second sort of challenge is outside the scope of this paper. Some interesting defences of a normative account of belief include Shah (2003), Shah \& Velleman (2005), and Wedgwood (2002). See also Zalabardo (2010) for a very compelling response to Shah \& Velleman's arguments for a normative account of belief; and Papineau (2013) for a very convincing response to this second sort of challenge to derivative accounts of norms of judgement.

${ }^{4}$ As I mentioned in the previous footnote, there is an important group of philosophers who are trying to argue for this additional claim (e.g. Shah, Velleman, and Wedgwood). My main aim here is not to argue against that view about the normativity of judgement, but rather to argue that a certain view about the nature of concepts (namely, that they are grounded in dispositions to be sensitive to certain principles of rationality) does not require us to endorse it.

${ }^{5}$ It could be argued that, according to the normative account of content, if Maura is not sensitive to the corresponding norms, then she does not possess our concept of 'yellow', but rather an alternative concept, 'yellow*', and then it does not make sense to say that she ought to form judgements of the form 'this is yellow' in reaction to certain experiences, given her moral and personal values, because she does not even possess our concept 'yellow' (at most, it might be the case that she ought to form judgements of the form 'this is yellow*' in certain circumstances, given her moral and personal values). In response, I think it makes perfect sense to say that Maura ought to form judgements of the form 'this is yellow' in certain circumstances, given her moral and personal values, even if she does not in fact possess the concept 'yellow'. It might still be of great moral or prudential value to her that she forms judgements involving the concept 'yellow' in certain circumstances, even if she does not in fact possess this concept. It could be argued, though, that this view is committed to the controversial claim that 'ought' does not imply 'can', since I am saying that she ought to form the belief 'this is yellow', even if she does not possess the concept 'yellow' (only 'yellow*'), and therefore she cannot form that belief. In my view, it seems plausible to say that in some relevant sense, she could come to acquire the required concepts, even if she does not currently possess them. In order to possess the concepts, she would have to acquire the relevant inferential dispositions that she does not currently have. But it seems possible that she might come to acquire them. Therefore, when we say that she ought to form the belief that this is yellow, even if she does not currently possess the concept 'yellow', this is compatible with the claim that she ought to believe p only insofar as she could believe $\mathrm{p}$ (assuming that she could eventually come to acquire the constituent concepts). Thanks to an anonymous reviewer for pressing me on this.

${ }^{6}$ It could be argued that if they have those false or unjustified beliefs, that is because they do not in fact follow those truth-conducive norms, since if they were following those truth-conducive norms in the first place, they would not have formed those beliefs that are contrary to evidence. In response, I would say, first, that perhaps the truth-conducive norms that are necessary in order to possess the constituent concepts and hence to entertain the corresponding beliefs do not require that one never forms those beliefs in the presence of contrary evidence; and secondly, even if these truth-conducive norms are indeed essential for entertaining those beliefs, we could say that a subject could still possess the constituent concepts and hence entertain the beliefs, given that they have the corresponding dispositions to follow those truth-conducive norms in normal conditions, even if in this particular case they are failing to manifest this disposition, given the presence of some non-standard conditions. In this case, then, it makes perfect sense to say that, on the one hand, the subjects have the disposition to be sensitive to those truth-conducive norms (even if they are failing to manifest this disposition at this particular occasion), compatibly with the normative theory of content; and on the other hand, that it is not the case that they ought to follow those truth-conducive reasons in this case, given that they value health or happiness more than truth, compatibly with Papineau's derivative account of norms of judgement. 